\title{
Open defecation-free slippage and its associated factors in Ethiopia: a systematic review
}

Thomas Ayalew Abebe* ${ }^{*}$ and Gudina Terefe Tucho

\begin{abstract}
Background: Recent studies have shown an increase in open defecation and slippage of open defecation-free certified villages in Ethiopia, despite significant progress the country made on sanitation programs. Hence, realizing of existing facts, this study was conducted aiming at a critical review of available literature and to provide consolidated data showing the level of slippage and its associated factors in Ethiopia.

Methods: Systematic literature searches were performed from four international databases. The search involved articles published from December 1, 2013, up to June 4, 2019. The Cochran's $Q$ and $P$ test statistics were used to check heterogeneity among the studies. To negotiate heterogeneity from qualitative data, we used a mixed-method approach. The researchers also conducted a publication bias assessment and sensitivity analysis. A random effect meta-analysis was employed to determine the pooled estimates of open defecation free slippage rate with a 95\% confidence interval (Cl). The data analysis was performed using the CMA V.3 software program.

Result: After screening 1382 studies, 12 studies were finally included in this systematic review. The estimated pooled rate of open defecation-free slippage in Ethiopia was 15.9\% (95\% Cl 12.9-19.4\%). The main contributing factors for open defecation-free slippage were lack of technical support, financial constraints, low-quality building materials, improper program implementation, and lack of sanitation marketing.

Conclusion: It was estimated that 1 out of 6 Ethiopian households engaged in open defecation after they have certified open defecation-free status, implying the low possibility of achieving sustainable development goals of 2030, which aims to ensure sanitation for all. Therefore, the government of Ethiopia and donors should better give special attention to the following options: (1) awareness for open defecation-free slippage, (2) launch a post-open defecation-free program, and (3) encourage research on pro-poor sustainable sanitation technologies.
\end{abstract}

Keywords: Defecation, Hygiene, Sanitation, Ethiopia

\footnotetext{
* Correspondence: ayalewthomas@gmail.com

Department of Environmental Health Sciences and Technology, Jimma

University, P.O. Box 387, Jimma, Ethiopia
}

C C The Author(s). 2020 Open Access This article is licensed under a Creative Commons Attribution 4.0 International License, which permits use, sharing, adaptation, distribution and reproduction in any medium or format, as long as you give appropriate credit to the original author(s) and the source, provide a link to the Creative Commons licence, and indicate if changes were made. The images or other third party material in this article are included in the article's Creative Commons licence, unless indicated otherwise in a credit line to the material. If material is not included in the article's Creative Commons licence and your intended use is not permitted by statutory regulation or exceeds the permitted use, you will need to obtain permission directly from the copyright holder. To view a copy of this licence, visit http://creativecommons.org/licenses/by/4.0/. The Creative Commons Public Domain Dedication waiver (http://creativecommons.org/publicdomain/zero/1.0/) applies to the data made available in this article, unless otherwise stated in a credit line to the data. 


\section{Background}

Globally, around 0.9 billion people practice open field defecation. Recent reports showed a drop in the number of individuals practicing open defecation in many regions of the world. However, sub-Saharan African countries increased the number of people defecating in the open field from 204 million to 220 million [1].

The reasons for increasing open defecation in SubSaharan Africa are high population growth and the slippage of open defecation-free (ODF)-certified communities, which refers to community member failure to keep fulfilling all open defecation free criteria. The investigation in African countries confirmed that the ODF slippage rate on the continent is $10-13 \%$ per year. Here, researchers defined the term ODF slippage based on sub-optimal latrine utilization and open field defecation [2].

In Ethiopia, the sanitation program has given special attention since 1995 after the government incorporated public health in the National Constitution. Subsequently, the Ministry of Health developed the National Hygiene and Sanitation Strategy and National Hygiene and On-Site Sanitation Protocol in 2005 and 2006 consecutively [3]. In 2006, an Irish NGO "VITA" introduced a sanitation tool called Community-Led Total Sanitation and Hygiene (CLTSH) program [4].

Community-Led Total Sanitation and Hygiene program is a better approach toward the reduction of open defecation practice and the achievement of the desired sanitation program. From 2011 to 2015, all Ethiopian administrative regions implemented a Community-Led Total Sanitation and Hygiene program covering more than $80 \%$ of the districts. According to the Ethiopian Ministry of Health report in 2015, 4657 kebeles (administrative villages) declared for open defecation-free status $[3,5]$.
Similarly, reports from the Ethiopian Demographic Health Survey indicated a decreasing trend of open defecation: $81.9 \%$ in $2000,61.9 \%$ in $2005,38.3 \%$ in 2011 , and $32.9 \%$ in 2016 [6-9]. The WHO and UNICEF Joint Monitoring Program data also showed that Ethiopia tremendously decreased open defecation between the years 2000 and 2015 (Fig. 1) [1]. However, a recent report showed that the practice of open defecation in Ethiopia is increasing in the same way it was rising in sub-Saharan African countries [3, 10], and approximately $35.6 \%$ of the population engaged in open defecation. This means that Ethiopia is off-tracking from the achievement of the Sustainable Development Goal (SDG), where half of the population still relies on unimproved sanitation facilities and 50\% latrine utilization [11].

The construction of more latrines does not ensure a drop in disease among people, especially children. However, open defecation-free status will reduce the occurrence of associated illnesses. Researchers confirmed that the prevalence of diarrhea was 7\% in ODF villages compared to $38 \%$ in OD villages [12]. Similar studies in Ethiopia also confirmed that the prevalence of underfive childhood diarrheal disease ranges from 9.9 to $17.2 \%$ in ODF villages and ranging from 23.2 to $36.3 \%$ in OD villages. Based on the WHO estimates, diarrhea contributes to more than one in every ten $(13 \%)$ child deaths in Ethiopia [6, 13-15]. Moreover, open defecation also contributes significantly to the prevalence of neglected tropical diseases in Ethiopia, including intestinal worms, schistosomiasis, and trachoma. For example, some researchers reported that children were between 2.7 and 7.53 times at higher risk of active trachoma when they lived in OD prevalent households. These children will be blind as a result of repeated episodes of infection

\section{Open defecation Practice (\%)}

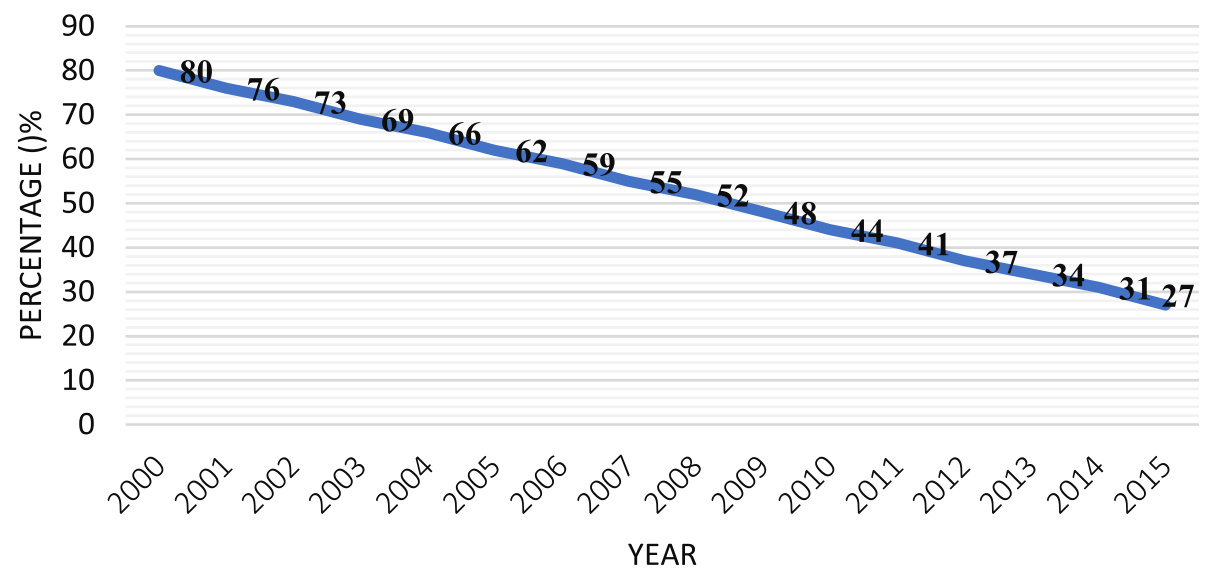

Fig. 1 Open defecation status in Ethiopia from 2000 to 2015 (source: SH.STA.ODFC.ZS) 
[16-18]. Therefore, the increment of open defecation will aggravate morbidity and mortality, particularly in children, which in turn affects the country's socioeconomic development.

Recently, increasing open defecation in Ethiopia was also due to open defecation-free slippage and high population growth. Most of Ethiopia's ODF villages slipped back between 1 and 2 years of ODF certification [19]. Studies conducted regarding open defecation-free slippage rates in different parts of the country have shown varying results and conclusions. These studies reported a slippage rate between 7 and $28.4 \%$. The indicators used to measure open defecation-free slippage and associated factors for slippage were also varied [2, 20]. Furthermore, a comprehensive study showing the country's open defecation-free slippage rate with contributing factors was unavailable to guide policy reform and health planning.

So, this review aimed primarily to conduct a systematic review of the available literature of open defecation-free slippage rates in the country and to provide consolidated data showing the level of slippage and its associated factors. This review will provide comprehensive information contributing to policy reform on sanitation and hygienerelated health planning. It will also serve as baseline data for further study.

\section{Methods}

\section{Review approach}

We have employed a systematic review to estimate the pooled open defecation-free slippage rate and to determine the triggering factors of ODF slippage in Ethiopia. A mixed-method approach was used in this systematic review to assimilate data that have a qualitative nature (verbatim quotes and views) and quantitative data, whereas meta-analysis was also used to pool and present the data with a quantitative nature obtained from various studies [21]. The mixed-method is an integrative review, synthesizing the quantitative and qualitative data together [22]. The findings from this review were reported using the Preferred Reporting Items for Systematic Reviews and Meta-Analyses (PRISMA) tool or checklist (see S1 Table A) [23]. This systematic review was registered and available at PROSPERO ID CRD42020146950.

\section{Searching strategies}

Systematic reviews containing registered protocols were primarily explored to avoid duplication. We have also systematically explored articles and grey literature from international databases including Cochrane Library, PubMed, Google Scholar, and Science direct. The following search terms "Open Defecation OR Open Defecation-Free OR Open Defecation-Free Slippage OR Community-Led Total Sanitation AND Ethiopia" were used separately and along with the Boolean operators like "OR" or "AND" to get published articles and grey literature. Our search was performed from December 1, 2013, to June 4, 2019 (see S2 Table B).

\section{Study inclusion criteria}

We used the following inclusion criteria for screening of the studies: (a) articles dealing with open defecation, open defecation free, open defecation-free slippage, and Community-Led Total Sanitation; (b) all kinds of study designs; (c) articles in which the outcome measures were an open field defecating households in open defecationfree villages or ODF slippage rate (event rate); (d) article in which ODF is achieved only through CLTSH program or intervention; (e) articles in which determining factors for open defecation-free slippage were described; (f) published full-text articles and unpublished grey literature; (g) articles published in the English language; (h) studies conducted in Ethiopia; and (i) articles published between December 1, 2013, and June 4, 2019. Articles which did not meet the above criteria were excluded from the study.

\section{Data abstraction}

Two researchers Thomas Ayalew Abebe (TAA) and Dr. Gudina Terefe Tucho (GTT) independently screened the titles and abstracts based on the inclusion criteria. They also removed duplicate articles. After removing duplicate articles, the full texts of the remaining articles were screened based on the inclusion criteria. The required information was extracted using a standardized data extraction format in Microsoft Excel and checked the data extraction process. These two researchers resolved their disagreements by consensus. The data extraction format included study characteristics such as the author name, region, study year, publication year, study design, study setting, sampling method, sample size, types of interventions to achieve ODF, ODF certification period, and open defecation-free slippage rate (event rate) (Table 1).

\section{Quality assessment}

To examine the risk of bias or methodological quality, we analyzed each article by using Hoy et al. [30] tool for prevalence studies. This instrument has 10 items used in two dimensions to evaluate the quality of studies: external validity (items 1-4: target population, sampling frame, sampling method, and non-response bias minimal) and internal validity (items 5-9: the data collection method, case definition, study instrument, and mode of data collection). Item 10 measures assessment-related bias. We also used a JBI Critical Appraisal Checklist for qualitative studies [31]. Two independent reviewers (TAA and GTT) critically assessed every article and addressed it. Finally, studies that scored low-risk bias were included in the systematic review (see S2 Table C and D). 


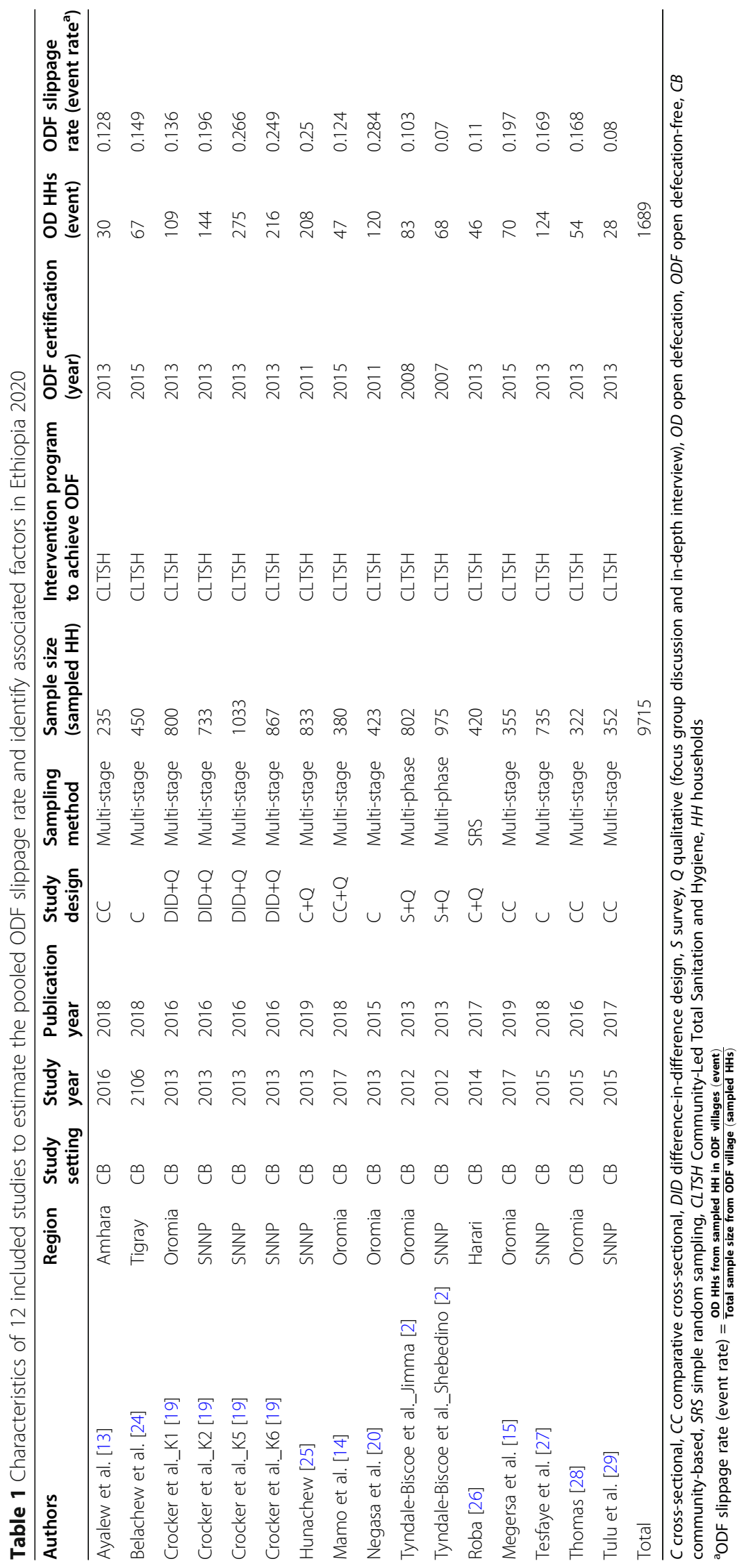




\section{Data analysis}

The extracted data were entered in Microsoft Excel format and analyzed using the Comprehensive MetaAnalysis version 3 statistical software. The heterogeneity was detected by reviewing the tables describing the included studies, reviewing the forest plots, and reviewing statistical tests. Heterogeneity in this review refers to the percentage of variation across studies. It was quantified using the inverse variance $\left(I^{2}\right)$. The $I^{2}$ ranges from 0 to $100 \%$. Hence, one rule of thumb categorized the $I^{2}$ values of $25 \%, 50 \%$, and $75 \%$ as low, moderate, and high heterogeneity, respectively, with a $p$ value less than 0.05 [32].

Besides, the random effect meta-analysis model was employed for approximating the Der Simonian and Laird's pooled effect [33]. The result was presented in the forest plot with respective event rates and 95\% confidence intervals. Subgroup analysis was also performed among regions, sample size, and study design to identify the source of heterogeneity. The logit-transformed data were used for multivariate meta-regression for further investigation of heterogeneity and to appreciate the proportion of individual moderator's effect on the heterogeneity between groups. Publication bias was detected with a visual inspection of funnel plots. Besides, Egger's test was used to test the statistical significant asymmetry of the funnel plot's statistical significant asymmetry, in which $p<0.05$ was considered significant [34]. To account for any publication bias, we used the trim-and-fill method to correct the funnel plot and adjust the pooled estimate of the ODF slippage rate or event rate. The technique is known as "trim and fill" as the method initially trims the asymmetric studies from the right-hand side or left-hand side to locate the unbiased effect (in an iterative procedure) and then fills the plot by re-inserting the trimmed studies on the right or on the left as well as their imputed counterparts to the left or the right of the mean effect. If this shift is trivial, one can have more confidence that the reported outcome is valid [35]. Finally, we conducted a sensitivity analysis to investigate whether the pooled prevalence estimates were influenced even by a single study [36], whereas ODF slippage determining factors from quantitative studies and verbatim quotes or views regarding ODF slippage from qualitative studies not be pooled together with the use of the conventional meta-analytic technique [37]. To assimilate findings and to realize a more in-depth understanding of all factors that caused open defecation-free slippage, the researchers have followed the triangulation protocol [38]. Traditionally, quantitative methods were used to describe relationships between outcomes, while qualitative methods were applied to reveal the causes and intentions. However, the complicated open defecation-free slippage factors can only be identified by combining qualitative and quantitative methods, as presented in the mixedmethod approach. This methodological approach (mixed- methods approach) incorporates qualitative data along with quantitative synthesis, which is a promising way of handling or negotiating heterogeneity [39].

This approach sets out to identify meta-themes across the studies from different methods, looking specifically at an agreement, partial agreement, or dissonance between these study findings. The mixed-method approach has been used in an Excel spreadsheet, contrasting themes from the qualitative and quantitative components, focusing specifically on inter-method discrepancies. Besides the previous methods, these integrated themes were presented following the structure of the quantitative analysis. The rate of open defecation-free slippage and the identified factors for open defecationfree slippage were the main findings of this systematic review.

\section{Results}

Study selection and characteristics of included studies

A total of 1382 studies were identified from international databases and grey literature. We excluded 266 duplicate articles after reviewing the titles and abstracts. Then, after reading the title and the abstract based on preset inclusion criteria, 1025 studies were omitted. Finally, 91 studies were screened for full-text review, and 12 articles were selected to estimate the pooled open defecationfree slippage rate and associated factor in Ethiopia. The remaining 79 studies were excluded because they did not fulfill the pre-defined inclusion criteria (Fig. 2).

We considered two articles [Tyndale-Biscoe et al. [2] and Crocker et al. [19]] as six studies because they included the slippage rate of 6 study areas (2 from the Oromia region and four from the $\mathrm{SNNP}^{1}$ region). We segregated these two studies rather than merging the findings to minimize biased generalization during pooling the open defecation-free slippage rates. This systematic review included 9715 households, five Ethiopian administrative regions, and four study designs, sample sizes ranging between 235 and 975. The open defecation-free slippage rate also varied across the districts. Shebedino district in the SNNP region showed the lowest slippage rate (7\%), whereas Kersa district in Oromia region showed the highest slippage rate (28.4\%) (Table 1).

\section{Pooled Open defecation-free slippage rate}

The result from the forest plot (meta-view) showed that 12 studies favored the risk of open defecation free slippage, whereas none of the studies favored ODF sustainability. If the event rate lies to the right of zero, it indicates open defecation-free slippage, and if it lies on zero, it shows open defecation-free status. However, here, zero has nothing to do with no effect. It only

\footnotetext{
${ }^{1}$ South Nation, Nationalities and Peoples (SNNP)
} 


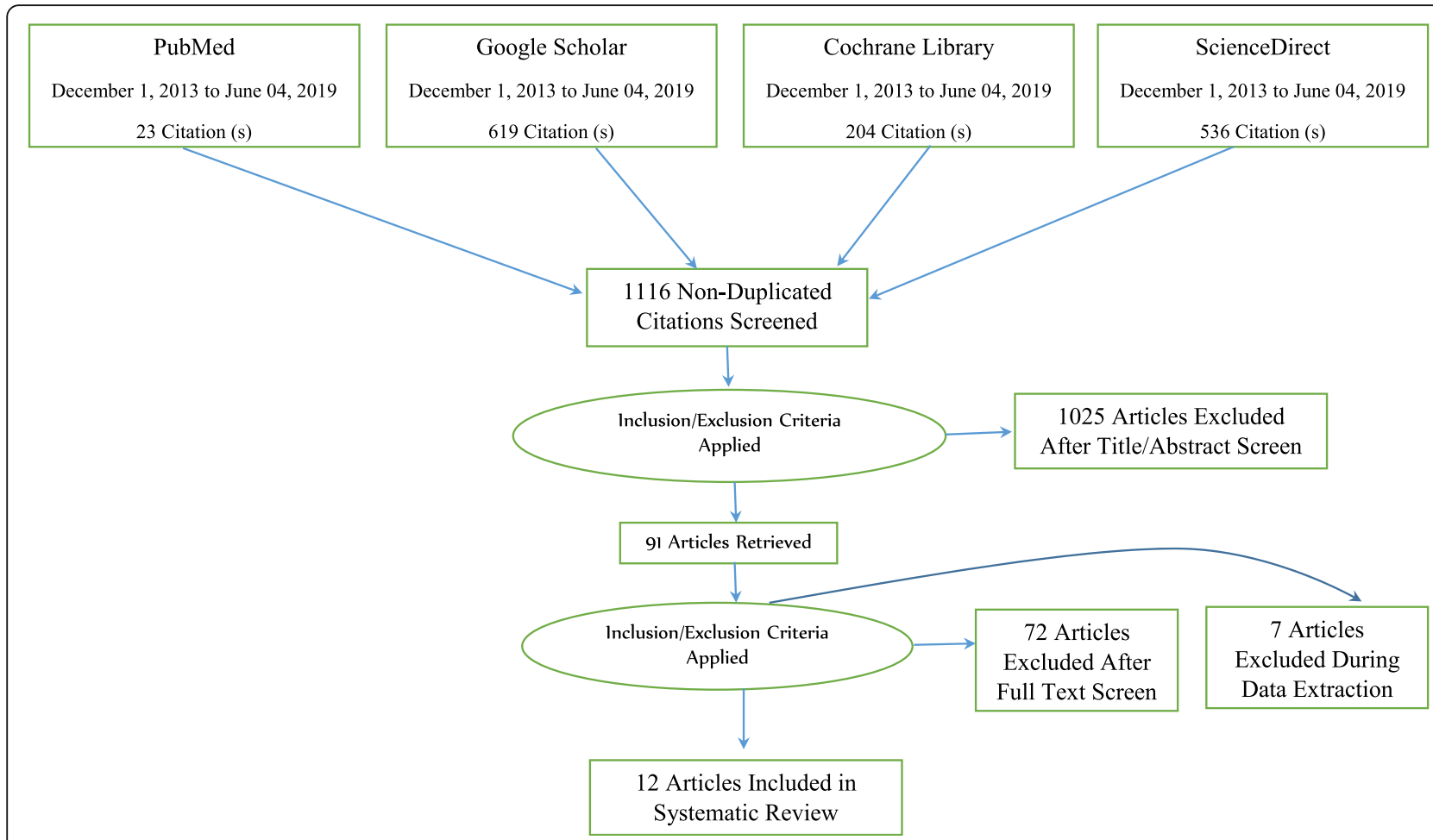

Fig. 2 PRISMA flow diagram of included studies considered for the systematic review

signifies no open defecation-free slippage or open defecation-free status. The data of open defecation-free slippage do not lie to the left side of zero because there was no negative effect size in this area of study. Open defecation free slippage data always skewed to the right or aligned on the centerline.

The overall result from the forest plot (meta-view) favored open defecation-free slippage because the red diamond fell to the right of the centerline. The red diamond represents a summary of the pooled open defecation free slippage rate of the studies.

Hence, the results of 12 included studies in the metaanalysis showed that the pooled open defecation-free slippage rate in Ethiopia was 15.9\% (95\% CI 12.9-19.4\%). Heterogeneity was also high $\left(I^{2}=95 \% ; P<0.0001\right)$. Therefore, the researchers used random-effects meta-analysis for controlling heterogeneity. The significant magnitude of heterogeneity also suggested conducting subgroup analysis to identify the source (Fig. 3).

\section{Publication bias assessment}

On visual inspection, the funnel plot was found to be asymmetric (see S3 Figure A), and Egger's test of the intercept $\left(B_{0}\right)$ came to be $-10.76(95 \%$ CI -16.80 , $4.71 ; P=0.002)$. This suggested the existence of publication bias that requires the trim-and-fill method to adjust the final pooled effect size. However, the trim-and-fill techniques indicated no studies were missing, and ODF slippage rate was unchanged based on a random-effects model (see S3 Figure B and C). According to the sensitivity test, we found the source of Funnel plot asymmetry was due to the segregation of two studies [Tyndale-Biscoe et al. and Crocker et al.] for the issues of generalization. But when we merged the results of these studies, the pooled ODF slippage rate was decreased to $15.6 \%$ and heterogeneity between studies increased to $95.5 \%$, whereas the finding from the egger test showed statistically insignificant $(P=0.11)$ with the intercept $\left(B_{0}\right)$ of -4.66 (95\% CI - 10.52, 1.21). Therefore, the reported ODF slippage rate $(15.9 \%)$ is valid, and funnel plot asymmetry did not arise from publication bias.

\section{Subgroup analysis and meta-regression}

We accompanied a subgroup analysis based on the study area, sample size, and study design (Table 2). When limiting our analysis to the study area, SNNP region showed the highest open defecation-free slippage rate of $17 \%$ (95\% CI $12.3-23 \%)$ followed by the Oromia region with pooled open defecation-free slippage rate of $16.1 \%$ (95\% CI 11.6$22.1 \%)$, but not statistically significant $(p=0.215)$ difference.

When restricting our analysis based on sample size $(<$ 500 and $\geq 500$ ), the sample size $\geq 500$ subgroup had a higher open defecation-free slippage rate of $16.9 \%$ (95\% CI $12.5-22.4 \%$ ), whereas sample size $<500$ had $14.8 \%$ (95\% CI 11.0-19.7\%); however, the difference between the groups was not statistically significant $(p=0.546)$. 


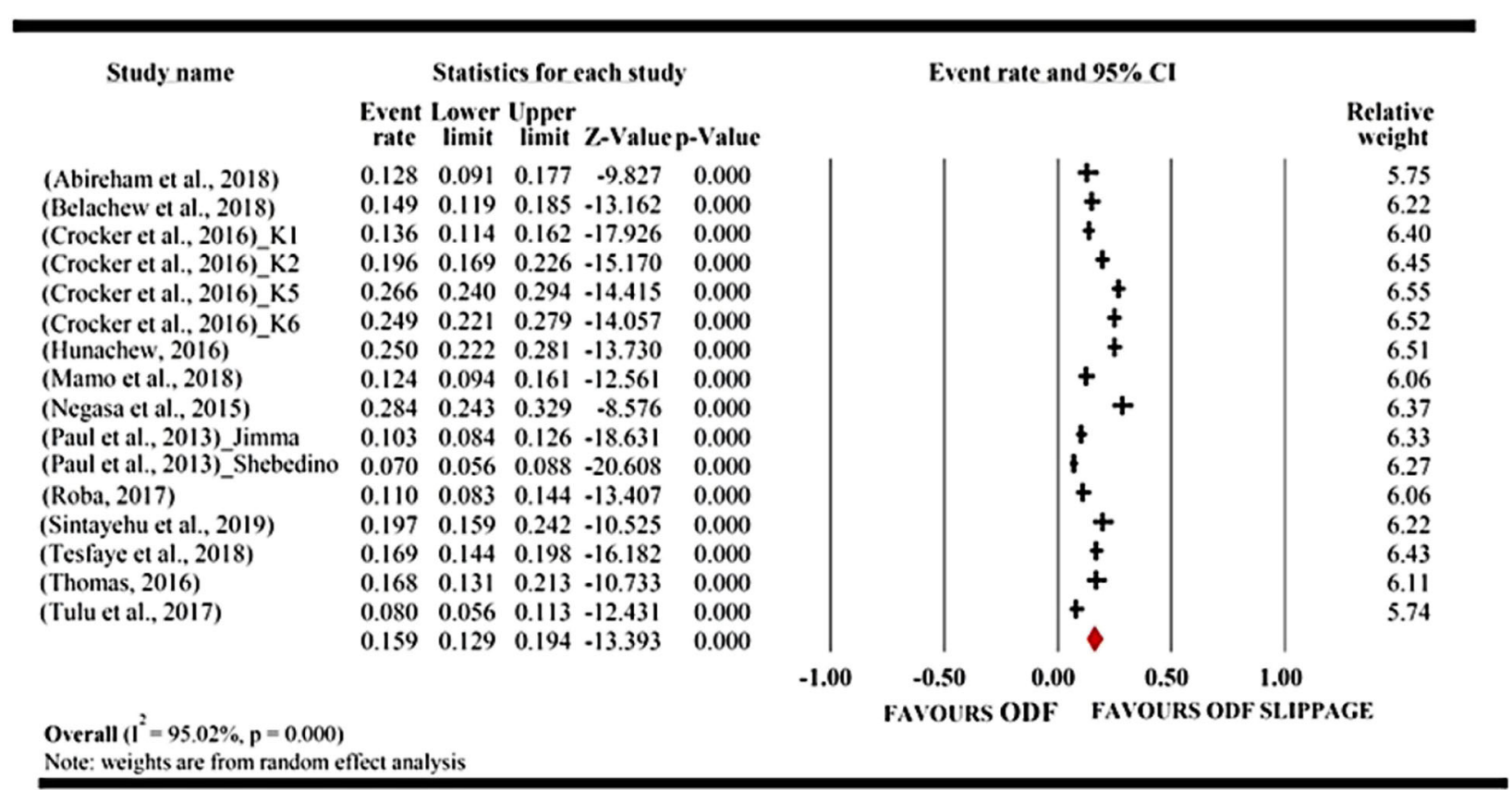

Fig. 3 Forest plot of the pooled open defecation-free slippage rate in Ethiopia: meta-analysis

Finally, when restricting our analysis by study design, the open defecation-free slippage rate was greater in the difference-in-difference design $(25.40 \%)$ and lower in the survey (8.6\%). In addition, heterogeneity between studies was statistically significant ( $p$ value $<0.001$ ).

The presence of statistically significant heterogeneity from univariate subgroup analysis on the study design motivated us to conduct meta-regression, Thus, we found that only study design has a statistically significant heterogeneity with $Q=13.48$ and $p=0.0037$. Hence, the study design explained $37 \%\left(R^{2}\right.$ analog $=$ 0.37 ) of the heterogeneity between studies. The remaining unexplained heterogeneity was from the data (see S2 Table E).

Table 2 Subgroup analysis of open defecation-free slippage rate in Ethiopia, 2020

\begin{tabular}{|c|c|c|c|c|c|c|c|}
\hline \multirow[t]{3}{*}{ Subgroup } & \multirow{3}{*}{$\begin{array}{l}\text { Number } \\
\text { of studies }\end{array}$} & \multicolumn{6}{|c|}{ Statistics for each study based on random model } \\
\hline & & \multirow[t]{2}{*}{$\begin{array}{l}\text { Event } \\
\text { rate }(\%)\end{array}$} & \multirow[t]{2}{*}{$\begin{array}{l}\text { Lower } \\
\text { limit (\%) }\end{array}$} & \multirow[t]{2}{*}{$\begin{array}{l}\text { Upper } \\
\text { limit (\%) }\end{array}$} & \multicolumn{2}{|c|}{$\begin{array}{l}\text { Heterogeneity across the } \\
\text { studies }\end{array}$} & \multirow{2}{*}{$\begin{array}{l}\text { Heterogeneity between the studies } \\
p \text { value }\end{array}$} \\
\hline & & & & & $P^{2}$ & $p$ value & \\
\hline \multicolumn{8}{|l|}{ Region } \\
\hline Amhara & 01 & 12.8 & 9.1 & 17.7 & 0.00 & 1.00 & 0.215 \\
\hline Harari & 01 & 11.0 & 8.3 & 14.4 & 0.0 & 1.00 & \\
\hline Oromia & 06 & 16.1 & 11.6 & 22.1 & 93.34 & 0.000 & \\
\hline SNNP & 07 & 17.0 & 12.3 & 23.0 & 96.61 & 0.000 & \\
\hline Tigray & 01 & 14.9 & 11.9 & 18.5 & 0.00 & 1.00 & \\
\hline \multicolumn{8}{|l|}{ Sample size } \\
\hline$\geq 500$ & 08 & 16.6 & 15.3 & 18.1 & 91.10 & 0.000 & 0.546 \\
\hline$<500$ & 08 & 19.4 & 18.4 & 20.4 & 96.72 & 0.000 & \\
\hline \multicolumn{8}{|l|}{ Study design } \\
\hline Comparative cross-sectional & 05 & 14.5 & 12.9 & 16.3 & 82.25 & 0.000 & $<0.001$ \\
\hline Cross-sectional & 05 & 20.5 & 19.0 & 22.1 & 93.64 & 0.000 & \\
\hline Difference-in-difference & 04 & 22.2 & 20.8 & 23.6 & 94.15 & 0.000 & \\
\hline Survey & 02 & 8.6 & 7.4 & 10.0 & 83.60 & 0.000 & \\
\hline
\end{tabular}


Pooled factors for open defecation-free slippage

The results in Fig. 4 show the summary of the analyzed factors for open defecation-free slippage from quantitative and qualitative studies using a mixed-method approach. The most appeared theme in 13 studies or $81 \%$ of research documents was the lack of technical advice or capacity building as the leading cause of open defecation-free slippage, while the least appeared theme in $6 \%$ study was inaccessible sanitation marketing.

\section{Discussion}

\section{Open defecation-free slippage rate}

The analysis revealed that the open defecation-free slippage rate in Ethiopia was 15.9\% (95\% CI 12.9-19.4\%). This slippage rate was higher than a study conducted in Nepal $3.5 \%$ [40], in Ghana 8.8\% [41], and in Indonesia 14.5\% [42], consecutively. Similarly, the slippage rate was higher than the average slippage rate of some African countries, which was $10-13 \%[2,43]$, in contrast, lower than East Timor 16.4\% [44], Benin 17.5\%, Mali and Mauritania 24\% [41], Kenya 22\% [2], Eritrea 27\% [45], and Mozambique 31\% [46] (Fig. 5). The reasons for open defecation-free slippage rate differences were implementation frameworks, socioeconomic status, and study design.

\section{Factors contributing to open defecation-free slippage}

The researchers of this review identified many factors for open defecation-free slippage that have emerged from qualitative content analysis and quantitative assessments and grouped these factors as socio-economic, technical, and policy-related issues.

\section{Socioeconomic issues}

Discomfort to use shared latrines Nineteen percent of the selected studies indicated shared toilets as a contributing factor for open defecation-free slippage. Studies conducted in 13 African countries also confirmed that sharing latrines brought frustration even among family members. The poorest people without option and sharing toilet from their neighbors slipped back to open defecation [47]. However, regular latrine sharers were relatives of latrine owners or the same family members or latrine co-investors. Sharers feel extreme embarrassment of asking to use the toilet regularly due to social taboos that prohibited them. Sharers feel ashamed of sharing the toilet with owners and subjected to a long waiting line (queue), which discouraged them from regular utilization of shared latrines [48]. A study report from Kenya similarly showed that sharing latrine with neighbors has a significant contribution for open defecation-free slippage [49]. Therefore, sharers remain or continue defecating in open field until they own private latrine.

Financial constraints Seven (44\%) of the research documents revealed that the reason for open defecation-free

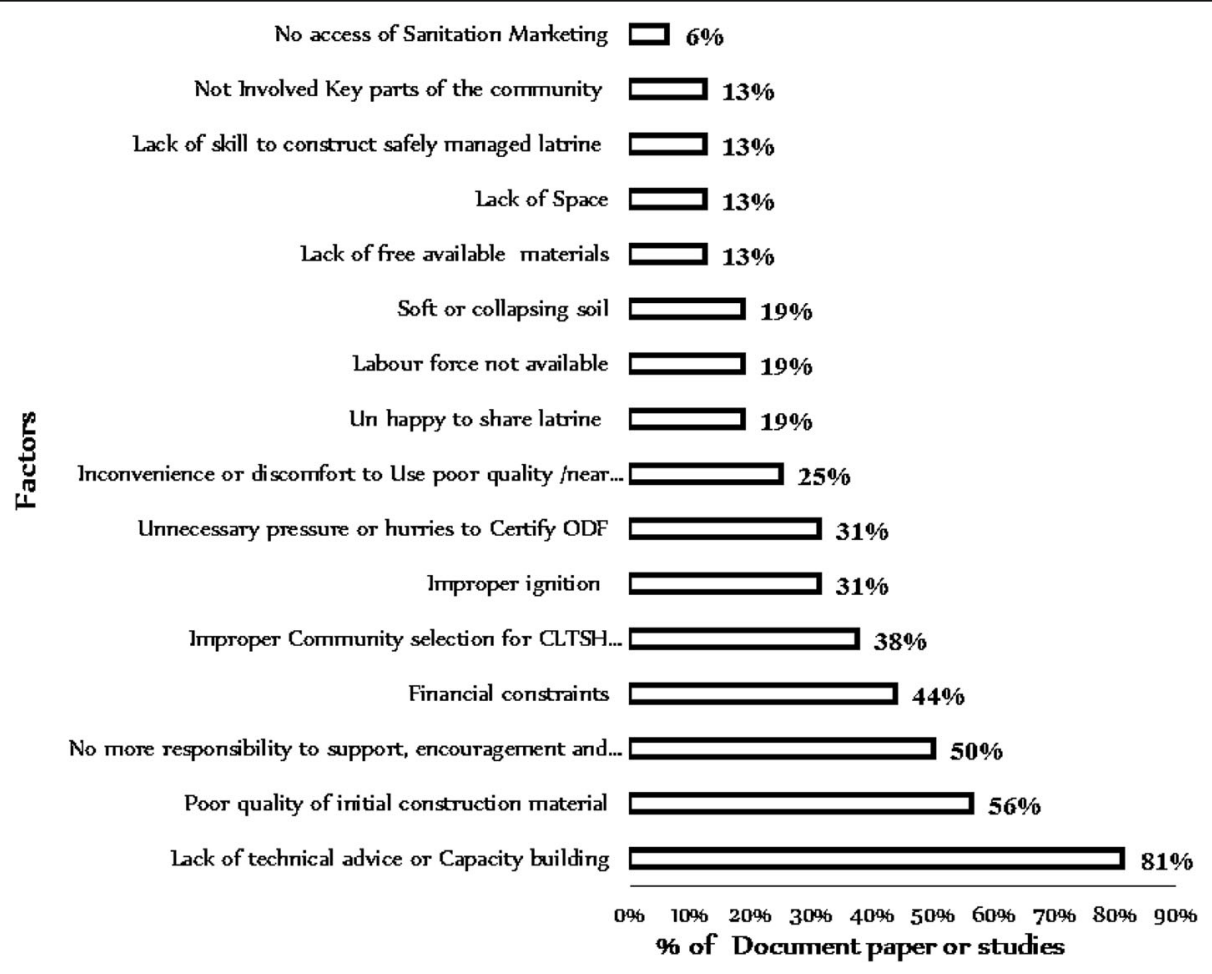

Fig. 4 Factors for open defecation-free slippage in Ethiopia, 2020 


\section{ODF slippage rate}

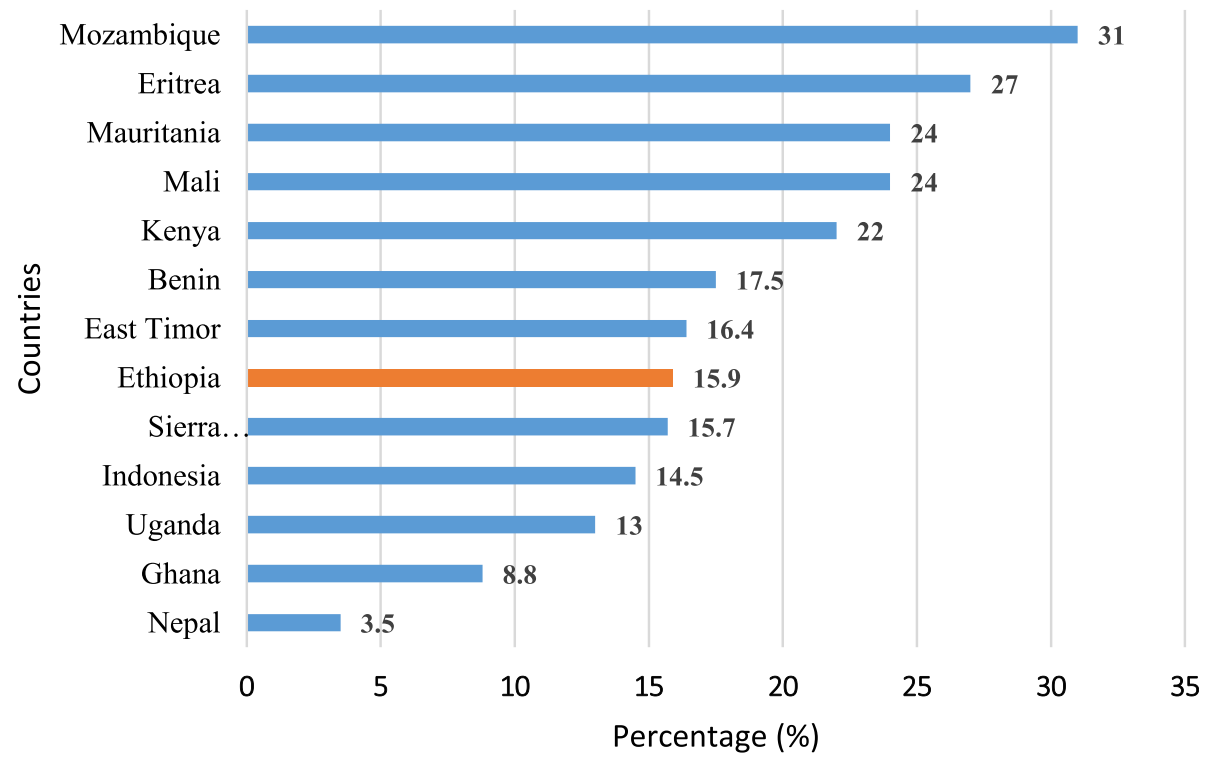

Fig. 5 Distribution of open defecation-free slippage rate in some countries, 2020

slippage was lack of money for maintenance. For this reason, they slipped back to open defecation or stopped using their latrines [50]. Most poor households cannot sustain open defecation-free status or rebuild a highquality toilet (which stays longer) without financial support [43].

Lack of space Some studies reported it as a contributing factor for open defecation. Households with filled latrines start open defecation because of inadequate space for reconstruction [4]. A similar report in Zambia revealed that the reason behind open defecation-free slippage was land constraint or inability to manage filled latrines [51]. Limited availability of land, especially among disadvantaged people, leads to continued open defecation practice $[44,52,53]$. Households with space or land can easily reconstruct their latrine with any available materials [40].

Lack of freely available materials Thirteen percent (13\%) of the reviewed studies showed a lack of freely available materials which was a barrier for sustaining open defecation-free status. The impact was high among poor people with limited free access to durable materials. Thus, latrine construction using short-lasting materials results in low-quality latrine and elevated open defecation-free slippage [52]. A survey from Katete District Eastern Zambia indicated that people must travel approximately $10 \mathrm{~km}$ to get freely accessible materials used for constructing or maintaining latrines [54]. The subsidies for freely available materials in Indonesia empowered poor communities to build their toilet [55]. Thus, locally available materials can strengthen the sustainability of open defecation-free status through acceptable subsidies. Otherwise, the use of lowquality materials for constructing a latrine basement and supper structure will facilitate to an easily collapsible and impermanent toilet, which triggers open defecation. For instance, using defective construction materials such as mud or grass will lead to frequent latrine collapse and open defecation practices [56].

\section{Technical issues}

Lack of technical support Thirteen (81\%) research documents reported a lack of technical support as contributing factors for open defecation-free slippage. The evaluation of Community-Led Total Sanitation and Hygiene effectiveness in 8 African countries similarly stated that interventions designed to advise on upgrading and improving sanitation facilities using local materials maintain open defecation-free status [57]. Sanitation programs should include information and advice on various low-cost toilet designs and options [43]. If communities wonder how to create and express their need for sustainable latrines, the facilitators of CLTSH should provide technical advice [4].

Lack of skill Lack of skill to construct safely managed latrine is another underlying factor for open defecation-free slippage. Usually, unskilled persons build a highly collapsible toilet. Latrine construction skills and technical advice help in the selection of better locally available materials and the correct latrine design. The unskilled person is 
unable to innovate good-quality latrine design. The few innovators available in the village were also unwilling to share their skills for others. Thus, most of the existing toilets were identical and unsanitary [58]. People built what they saw in their neighbors. For instance, a report from the Houaphanh Province of Lao showed that most of the toilets were 1 meter or less deep, with floors and walls constructed of temporary wooden poles or bamboo and a squatting hole with no lid cover, and many toilets were dirty [59]. Research in Kenya also shows that people copied most of the latrine prototypes from previously built toilets with limited knowledge based on the advice of their leaders. These lower-quality latrines had no privacy, unpleasant smell, and technical faults. Some common technical errors were the depth of the pit, shape, and absence of a lid on a slab hole [43]. Thus, the absence of practical guidance and lack of skilled labor in the community frequently results in low-quality unhygienic toilets and the preference of open defecation $[44,48,60]$.

Poor quality of toilet Poor quality of toilet was one of the contributing factors for open defecation-free slippage, as reported in $25 \%$ of the analyzed research. Poor-quality latrine pushes back users because of unaesthetic conditions (unpleasant smell or no privacy). Similarly, a study conducted in seven developing countries reported poor-quality latrine was a primary challenge for the sustainable use of a toilet in open defecation-free villages [61]. Supporting a study conducted in Kampala, Uganda, also showed that owning dirty and malfunction toilets descended the sanitation ladder back to open defecation because people were scared of falling in this toilet or gaining the disease from it [62]. Another study in India indicated that the construction of low-cost temporary latrine contributes to the slippage of open defecation-free practice [63]. A high-quality toilet can sustain open defecation-free status for a prolonged time, while a short-lived latrine discourages individuals from using or preferring open defecation [43].

Soft collapsible soil Soft collapsible soil was another contributing factor for frequent latrine collapse and open defecation. The study conducted in Mozambique illustrated that $60 \%$ of people did not rebuild their latrine in sandy soil [64]. Latrine construction on sandy soil will have only a few months of life $[65,66]$. People who built their toilet on sandy soil fell back to open defecation because of latrine collapse [67, 68].

\section{Policy issues}

Improper ignition or triggering Improper ignition or triggering theme frequently appeared in five analyzed papers $(n=5,31 \%)$. Improper CLTSH triggering drove people to open defecation-free slippage. So, attention for the three elements of CLTS triggering (shame, disgust, and fear) can have a long-lasting effect on sustained hygienic behavior [4]. A study report from $80 \mathrm{CLTSH}$ triggered villages of East Java showed a significant relationship between better quality triggering and sustained open defecation-free status [50, 60,69].

Early certification of ODF Early certification of ODF appeared in $31 \%(n=5)$ of the analyzed documents. The unacceptable pressure on communities for early certification of ODF will contribute to slippage. Technology acceptability and changing behavior toward its utilization require a sufficient time of adoption. The ODF certification based on social pressure and solidarity has a longterm effect on ODF sustainability $[4,70]$. The exertion of tension by political leaders to declare open defecation-free ends up with unreal ODF status, while the communities were defecating in the open field [71]. Therefore, programmers should understand the reality of losing established facilities or preference of habitual behavior under tense pressure of implementation [72].

Lack of involvement In 16\% ( $n=2)$ of the research papers, the lack of enrollment comprehends all segments of the population in the sanitation system led to ODF slippage. Most programs ignored engagement, particularly disadvantaged people such as needy families, elders, children, disabled persons, women, and other vulnerable community members. Ignoring these groups of people affects the sustainable performance of open defecation-free status. An evaluation report in Sierra Leone depicted that children who continued open defecation were students who went to school exactly at the same time as CLTSH triggering or who did not attend the CLTSH triggering event [73]. Another study conducted in 6 regions of Eritrea concluded that people who missed attending an ignition or CLTSH triggering moment could not stop open defecation [45]. Villages with more robust community involvement also have a low open defecation-free slippage rate [42]. A research report from Abidjan, Ivory Coast, also confirmed that "the effective sanitation interventions involve women and religious groups" [74]. The involvement of these groups is a critical stage for open defecation-free sustainability. Poor and disadvantaged households are at a much higher risk of open defecation-free slippage. Furthermore, they have a higher gap in sanitation and hygiene services because of equity and inclusion issues. The roles of women, adolescent girls, and boys need harmonization and integration in WASH programs. For example, women are more active and motivated than men to stop open defecation due to women shoulder most of the household activities [43, $48,55,75]$. Therefore, the best way to open defecation-free sustainability relies on empowerment, equity, inclusion, 
consultation, and consideration of marginalized people in policy or program implementation.

\section{Policy implications}

The 2030 sustainable development agenda comprises 17 goals and 169 targets. It included all nations across the world. In 2015, these countries introduced SDGs to end poverty and hunger, to protect the planet from destruction, to ensure prosperous life, to promote stability, and to build alliances. The SDGs' strategic implementation target will be achieved by integrating the economic, social, and environmental aspects together over the next decade in areas of critical importance to humanity and the planet [76]. However, recent open defecation-free slippage is a severe obstacle to the achievement of the SDG target, in particular SDG 1 and SDGs 3-6.

\section{How does ODF slippage affect SDG?}

Eradication of poverty (SDG 1) Our world loses 7 billion USD per year for health services because of sanitationrelated diseases [77]. Open defecation is associated with child health and growth, which results in stunting $[78,79]$. Stunting diminishes educational and productivity outcomes $[50,80,81]$. Recently released econometric reports have revealed that open defecation affects the national economy $[79,82,83]$. For instance, Kenya loses $\$ 88$ million per year because of open defecation-related health impact. They spent this money on health care, medicines, and treatment. Correspondingly, open defecation-related diseases result in the loss of several working days [80]. It requires further research to know the econometric relationship between health and ODF slippage.

Creation of a healthy society (SDG 3) Scientists noted poor sanitation as the cause of morbidity and mortality for the first time in 1842 and considered it as "great sanitary awakening" [84]. Open defecation is the most dangerous poor sanitation practice because $1 \mathrm{~g}$ of fresh feces carries $10^{6}$ viruses, $10^{6-8}$ bacteria, $10^{4}$ protozoan cysts, and $10^{1-4}$ helminth eggs [85]. Open defecation also plays a significant role in the transmission of infectious diseases; neglected tropical diseases and malnutrition, such as diarrhea, cholera, typhoid, shigellosis, hepatitis, helminths, trachoma, schistosomiasis, or bilharziasis; stunting; growth retardation; and anemia [86-90]. For example, the outbreak of cholera is associated with drinking water contaminated with feces [91]. The diarrheal disease kills more than 1.6 million under-five children every year, mainly because of poor sanitation [92]. Soil-transmitted helminths spread and re-infects in an open defecation-free slipped environment because ovas of helminths live in soil up to 2 years [93, 94]. Open defecation-free slippage also leads to the spread of trachoma - the leading cause of blindness
[28, 87, 95]. Besides, intestinal schistosomiasis is prevalent in countries where open defecation is endemic [96-100]. Another common waterborne disease related to open defecation-free slippage is hepatitis (hepatitis A and hepatitis E). The occurrence of hepatitis is through contamination of drinking water sources with feces. Particularly, hepatitis E (emerging pathogen) will be dangerous for the life of pregnant women in open defecation-free slipped villages $[101,102]$.

Bringing inclusive, fair, and high-quality learning environments (SDG 4) Open defecation practice cannot ensure privacy, dignity, safety, user-friendly, and a complete learning environment. Exposing school children to open defecation leads to an increased risk of respiratory, gastrointestinal, neurocognitive, and psychological illnesses [103-105]. The lack of safe sanitation services in schools also increases school absenteeism, especially for girl students [77, 103, 106-108]. School absenteeism can lead to low-grade achievement (low academic performance), failure to pass classes, increase drop-out rates, and delays in social development [106, 109-111], which restrains children from gaining economic and health benefits related to educational achievement [112].

Ending open defecation by 2030 (SDG 6) Ending open defecation by 2030 (SDG 6) will be difficult because of open defecation-free slippage. The planet has reduced open defecation radically since 2000, except for subSaharan Africa and Oceania. WHO and UNICEF reported that the factor for increment in open defecation was high population growth. However, the researchers of this review argue that population growth was not the only reason for open defecation increment, but the occurrence of open defecation-free slippage was another factor for the increment [1]. If ODF slippage continues, ending open defecation by 2030 will be fictitious altogether with the achievement of universal sanitation access and ascent to the sanitation ladder.

\section{The implication of ODF slippage in Ethiopia}

Ethiopia is one of the top-piloted countries where open defecation tremendously decreased between the years 2000 and 2015. Even though the country has many most effective enabling environments, the reality depicts behavior change, and the implementation process through total sanitation and hygiene program is in back-andforth progress because of emerging ODF slippage.

Open defecation-free slippage will be an obstacle for achieving the Ethiopian Health Sector Development Plan (HSDP) in decreasing the percentage of households using latrines and the proportion of villages (kebeles) free of open defecation [113]. Moreover, open defecation-free slippage leads to the failure of the One WASH National 
Program (OWNP), which intended to achieve three primary hygiene and sanitation behaviors such as use safely managed excreta, apply a safe water chain from a safe source to the mouth, and wash hands with soap or a substitute after defecation [114]. It will also affect the performance of the Ethiopian Second Growth and Transformation Plan (GTP). GTP II focused on tripling improved household latrine coverage from $28 \%$ in 2015 to $82 \%$ by 2020 , as well as doubling the ODF kebeles from 27 to $50 \%$ by the end of the 2018/2019 budget year, but the WASH sector extended this period to 2024 due to deadline $[115,116]$. The challenge goes to the success of the Ethiopian National Hygiene and Sanitation Strategy (NHSS) that basis on new thinking and effort to shift the sluggish annual growth rate $(1.2 \%)$ of improved household latrine to reach $51 \%$ by the end of 2020 . NHSS does not safeguard the environment and society unless this ODF slippage ceases to exist with the introduction of innovative ideas to stop slippage. Besides, it would take another 25 years to achieve $51 \%$ of improved sanitation facilities [117].

The prevalence of waterborne diseases and neglected tropical diseases (especially soil-borne helminths, trachoma, and schistosomiasis) is increasing in Ethiopia due to open defecation-free slippage. These diseases increase maternal and childhood morbidity and mortality, which in turn impacts the economic development of the country $[15,118-120]$.

\section{Alternative sanitation policy}

Policy modification for equity and inclusion of poor and marginalized groups contributes to greater ODF sustainability. Therefore, it requires prioritization of the following activities at different levels.

At a technical level, it is crucial to identify the best hygiene promotion approach and affordable sanitation technology and determine the minimum cost that will not discriminate the poor and marginalized groups. The strengthening of best approaches such as Community-Led Total Sanitation and Hygiene program and school WASH program will achieve sustained open defecation-free communities. The program like post-open defecation-free follow-up should be incorporated in the National Sanitation Program.

At the government or donor level, the strategies and policies should better incorporate regular follow-up with measurable indicators. For example, including post-open defecation-free follow-up in the Community-Led Total Sanitation and Hygiene program will sustain the learned hygienic behavior. The government or donor should better consider the disadvantaged people who lack the resources (land or space, money, and local material) with acceptable subsidy programs because it will help them climb the sanitation ladder from a shared toilet to a private toilet or from a simple pit latrine to an improved sanitation facility. The increment of budget allocation for sanitation and hygiene programs also has a significant impact on program sustainability [42].

At the researchers' level, it is necessary to identify and test improved sanitation technology and estimate their cost. For instance, strategies that integrate CommunityLed Total Sanitation and Hygiene with other low-cost technologies like ecological sanitation (biogas, Arboloo, urine-diverting dry toilets, and a twin pit) have a significant impact on open defecation-free sustainability. It is common for rural communities to dig new pit after filled latrines, and finally, no reconstruction space or land left because of no tradition of reusing the pit. Furthermore, they have no idea that human excrement is used as a source of energy and organic fertilizer.

Our findings indicate that applying these three alternatives helps eradicate open defecation or sustain hygienic behavior in the community. The existing National Sanitation and Hygiene strategy should include post-ODF program for the most straightforward implementation and for a better capacity to address ODF slippage. Finally, an appropriate sanitation technology selection, sanitation behavior remodeling, and assessing the levels of social belief help in sustaining open defecation-free status.

\section{Conclusion}

Even though Ethiopia has adopted Sustainable Development Goal and reduced open defecation for decades, still the progress of improved sanitation facility is steady, and the ODF-certified villages were also retiring. It was estimated that one out of six Ethiopian households engaged in open defecation after they certified ODF status. Therefore, the increment of open defecation practice in Ethiopia was due to open defecation-free slippage besides population growth.

The factors for open defecation-free slippage were lack of technical support, poor-quality construction material, lack of follow-up, financial constraints, improper implementation of Community-Led Total Sanitation and Hygiene program, demotivation due to the poor-quality latrine, demotivation using shared latrines, collapsible soil conditions, lack of freely available materials, lack of land, lack of involvement, and lack of promotion on sanitation marketing.

Consequently, to accelerate the elimination of open defecation, the government of Ethiopia and its partners should better consider the level of slippage and its associated factor. Furthermore, there should be an integration of post-open defecation-free program and multisectoral coordination in the sanitation program. Finally, the encouragement of further research on pro-poor improved sanitation technology will help the community in climbing the sanitation ladder. Therefore, it will be easy to attain sustainable open defecation-free status or end open defecation by the end of 2030 . 


\section{Supplementary Information}

The online version contains supplementary material available at https://doi.org/10.1186/s13643-020-01511-6.

Additional file 1. Table A. PRISMA 2009 Checklist for Open defecation free slippage assessment in Ethiopia, 2020.

Additional file 2. Supplementary tables B-E.

Additional file 3. Supplementary figures $A-C$.

\section{Abbreviations}

CLTSH: Community-Led Total Sanitation and Hygiene; EDHS: Ethiopian Demographic and Health Survey; GTP: Growth Transformation Plan; HSDP: Health Sector Development Plan; NHSS: National Hygiene and Sanitation Strategy; OD: Open defecation; ODF: Open defecation-free; OWNP: One WASH National Program; PRISMA: Preferred Reporting of Systematic Reviews and Meta-Analysis; SDGs: Sustainable Development Goals; SNNP: Southern Nation and Nationalities People; UNICEF: United Nations International Children's Emergency Fund; USD: United States dollar; WASH: Water, sanitation, and hygiene; WHO: World Health Organization

\section{Acknowledgements}

We would like to forward heartfelt thanks to Jimma University for facilitating a favorable environment and WiFi service. Second, we would like to thank Mr. Mekonnen Nigussie for his time spent and willingness to edit this manuscript. Finally, we would like to thank Mrs. Diribe Makonene and Mrs. Sinafikish Dekebo for their support and encouragement.

\section{Authors' contributions}

TAA: conception of the research protocol, study design, literature review, data extraction, data analysis, interpretation, and drafting of the manuscript GTT: data extraction and quality assessment, data analysis, reviewed and revised the entire section of the final document critically, and gave final approval of the version to be published. Both authors have read and approved the manuscript.

\section{Funding}

We got no funding for this study.

\section{Availability of data and materials}

Data will be available upon request of the corresponding author.

\section{Ethics approval and consent to participate}

Not applicable.

\section{Consent for publication}

Not applicable.

\section{Competing interests}

The authors declare that they have no competing interests.

Received: 10 June 2020 Accepted: 26 October 2020

Published online: 03 November 2020

\section{References}

1. Organization WH. Progress on drinking water, sanitation and hygiene: 2017 update and SDG baselines 2017.

2. Tyndale-Biscoe P, Bond M, Kidd R. ODF sustainability study. FH Designs Australia: PLAN International. 2013:1-181.

3. Research B-CD. Outcome evaluation of Community-Led Total Sanitation and Hygiene (CLTSH) Program in Ethiopia from 2012-2015. Addis Ababa: UNICEF; 2016.

4. Kar K, Chambers R. Handbook on community-led total sanitation. Brighton: Institute of Development Studies, University of Sussex; 2008. p. 1-51.

5. Health FMo. Health and health related indicator 2008. 2016.

6. Central Statistical AE, Macro ORC. Ethiopia Demographic and Health Survey 2000. Addis Ababa: Central Statistical Authority/Ethiopia and ORC Macro; 2001.

7. Central Statistical AE, Macro ORC. Ethiopia Demographic and Health Survey 2005. Addis Ababa: Central Statistical Agency/Ethiopia and ORC Macro; 2006.
8. Central Statistical AE, International ICF. Ethiopia Demographic and Health Survey 2011. Central Statistical Agency/Ethiopia and ORC Macro: Addis Ababa, Ethiopia; 2012

9. Central Statistical Agency CSAE, Icf. Ethiopia Demographic and Health Survey 2016. Addis Ababa: CSA and ICF. p. 2017.

10. Singeling M. To ODF and beyond: sharing experiences from the Pan African CLTS Programme; 2016. p. 6.

11. Leshargie CT, Alebel A, Negesse A, Mengistu G, Wondemagegn AT, Mulugeta $\mathrm{H}$, et al. Household latrine utilization and its association with educational status of household heads in Ethiopia: a systematic review and meta-analysis. BMC Public Health. 2018;18(1):901.

12. Sanan D, Moulik SG. Community-led total sanitation in rural areas: an approach that works. New Delhi, India: Water and Sanitation Program-South Asia, The World Bank. 2007;12.

13. Ayalew AM, Mekonnen WT, Abaya SW, Mekonnen ZA. Assessment of diarrhea and its associated factors in under-five children among open defecation and open defecation-free rural settings of Dangla District, Northwest Ethiopia. J Environ Public Health. 2018;2018:1-8.

14. Mamo ZD, Dawit ZW, Mokonnon TM. Diarrheal status and associated factors in under five years old children in relation to implemented and unimplemented community-led total sanitation and hygiene in Yaya Gulele. Pediatric Health, Medicine Therapeutics. 2018;9:109-21.

15. Megersa S, Benti T, Sahiledengle B. Prevalence of diarrhea and its associated factors among under-five children in open defecation free and non-open defecation free households in Goba District Southeast Ethiopia: a comparative cross-sectional study. Clinics Mother Child Health. 2019;16:324.

16. WoldeKidan E, Daka D, Legesse D, Laelago T, Betebo B. Prevalence of active trachoma and associated factors among children aged 1 to 9 years in rural communities of Lemo district, Southern Ethiopia: community based cross sectional study. BMC Infect Dis. 2019;19(1):886. PubMed PMID: 31651236. eng

17. Alemayehu M, Koye DN, Tariku A, Yimam K. Prevalence of active trachoma and its associated factors among rural and urban children in Dera Woreda, Northwest Ethiopia: a comparative cross-sectional study. Biomed Res Int. 2015;2015. eng.

18. Cumberland P, Hailu G, Todd J. Active trachoma in children aged three to nine years in rural communities in Ethiopia: prevalence, indicators and risk factors. Transactions Royal Society Tropical Med Hygiene. 2005;99(2):120-7. PubMed PMID: 15607339. eng.

19. Crocker J, Geremew A, Atalie F, Yetie M, Bartram J. Teachers and sanitation promotion: an assessment of community-led total sanitation in Ethiopia. Environ Sci Technol. 2016;50(12):6517-25

20. Negasa E, Abebe B, Gudina T. Implementation of Community-Led Total Sanitation and Hygiene Approach on the prevention of diarrheal disease in Kersa District, Jimma Zone Ethiopia. Sci J Public Health. 2015:3(5):669.

21. Higgins J, Thomas J, Chandler J, Cumpston M, Li T, Page M, et al. Cochrane handbook for systematic reviews of interventions. Wiley Online Library. 2008.

22. Hurley M, Dickson K, Hallett R, Grant R, Hauari H, Walsh N, et al. Exercise interventions and patient beliefs for people with hip, knee or hip and knee osteoarthritis: a mixed methods review. Cochrane Database Syst Rev. 2018; 4(4):CD010842-CD. PubMed PMID: 29664187. eng.

23. Moher D, Liberati A, Tetzlaff J, Altman DG. Preferred Reporting Items for Systematic Reviews and Meta-Analyses: the PRISMA Statement. Ann Internal Med. 2009;151(4):264-9.

24. Belachew A, Abrha M, Gebrezgi Z, Tekle D. Availability and utilization of sanitation facilities in Enderta district, Tigray, Ethiopia. J Preventive Med Hygiene. 2018:59(3):E219 PubMed Central PMCID: PMC6196372.

25. Hunachew B. Sanitation infrastructure sustainability challenges case study: Ethiopia. Sustainable sanitation for all: experiences, challenges, and innovations. 2016;135

26. Roba A. Assessment of the implementation of community-led total sanitation, hygiene, and associated factors in Diretiyara district, Eastern Ethiopia. PLOS ONE. 2017;12(4):e0175233.

27. Tesfaye A, Abel F, Zemichael G. Latrine utilization and associated factors among Kebeles declared open defecation free in Wondo Genet district, South Ethiopia. ISABB J Health Environ Sci. 2018;5(5):43-51.

28. Thomas A. Prevalence of trachoma and associated factors of children aged 1-9 years in Community Led Total Sanitation And Hygiene triggered village and none triggered in Girar Jarso Woreda, North Shoa, Oromia, Ethiopia. 2016.

29. Tulu L, Kumie A, Hawas SB, Demissie HF, Segni MT. Latrine utilization and associated factors among kebeles implementing and non implementing urban Community Led Total Sanitation and Hygiene in Hawassa town, Ethiopia. African J Environ Sci Technol. 2017;11(3):151-62. 
30. Hoy D, Brooks P, Woolf A, Blyth F, March L, Bain C, et al. Assessing risk of bias in prevalence studies: modification of an existing tool and evidence of interrater agreement. J Clin Epidemiol. 2012;65:934-9.

31. Lockwood C, Munn Z, Porritt K. Qualitative research synthesis: methodological guidance for systematic reviewers utilizing metaaggregation. Int J Evidence-Based Healthcare. 2015;13(3):179-87.

32. Rücker G, Schwarzer G, Carpenter JR, Schumacher M. Undue reliance on I 2 in assessing heterogeneity may mislead. BMC Med Res Methodol. 2008;8(1):79.

33. DerSimonian R, Laird N. Meta-analysis in clinical trials. Controlled Clinical Trials. 1986 1986/09/01/;7(3):177-88

34. Matthias E, George DS, Martin S, Christoph M. Bias in meta-analysis detected by a simple, graphical test. BMJ. 1997;315:629-34.

35. Duval S. The trim and fill method. Publication Bias in Meta-Analysis 2005. p. 127-144.

36. Copas J, Shi JQ. Meta-analysis, funnel plots and sensitivity analysis. Biostatistics. 2000;1(3):247-62.

37. Rao G, Lopez-Jimenez F, Boyd J, D’Amico F, Durant NH, Hlatky MA, et al. Methodological standards for meta-analyses and qualitative systematic reviews of cardiac prevention and treatment studies: a scientific statement from the American Heart Association. Circulation. 2017;136(10):e172-e94.

38. Farmer T, Robinson K, Elliott SJ, Eyles J. Developing and implementing triangulation protocol for qualitative health research. Qualitative Health Research. 2015;16(3):377-94.

39. Lorenc T, Felix L, Petticrew M, Melendez-Torres GJ, Thomas J, Thomas S, et al. Meta-analysis, complexity, and heterogeneity: a qualitative interview study of researchers' methodological values and practices. Systematic Reviews. 2016 2016/11/16;5(1):192.

40. Shrestha $S$, Ahmad T, Shrestha P, editors. Sustainability of ODF in Nepal. Transformation towards sustainable and resilient WASH services: Proceedings of the 41st WEDC Inter-national Conference, Nakuru, Kenya; 2018: cc WEDC, Loughborough University.

41. Jiménez A, Jawara D, LeDeunff H, Naylor KA, Scharp C. Sustainability in practice: experiences from rural water and sanitation services in West Africa. Sustainability. 2017:9(3):403.

42. Odagiri M, Muhammad Z, Cronin AA, Gnilo ME, Mardikanto AK, Umam K, et al. Enabling factors for sustaining open defecation-free communities in rural Indonesia: a cross-sectional study. Int J Environ Res Public Health. 2017;14(12):1572.

43. Bongartz P, Vernon N, Fox J. Sustainable sanitation for all: experiences, challenges and innovations: Practical Action; 2016.

44. Abdi R. Open defecation free sustainability study in East Timor 2015-2016. IDS. 2016.

45. Eritrea U. National ODF Sustainability Assessment 2015: UNICEF Eritrea; 2015.

46. UNICEF. Evaluation of the WASH Sector Strategy 'Community Approaches to Total Sanitation'(CATS). New York: UNICEF; 2014

47. House S, Ferron S, Cavill S. Scoping and diagnosis of the Global Sanitation Fund's approach to Equality and Non-Discrimination (EQND). Water Supply and Sanitation Collaborative Council, http://wsscc org/wp-content/uploads/ 2017/08/GSF-EQND-Study-EN pdf. 2017;34

48. Improving CLTS from a community perspective approach in Indonesia2012.

49. Singh S, Balfour N. Sustainability of ODF practices in Kenya. www.unicef.org 2015.

50. Venkataramanan V, Crocker J, Karon A, Bartram J. Community-led total sanitation: a mixed-methods systematic review of evidence and its quality. Environmental health perspectives. 2018;126(2):026001.

51. Zambia SN. Zambia Country Baseline Report: sustainable sanitation and hygiene for all results programme. 2014. https://snv.org/cms/sites/default/ files/explore/download/p1-za1_baseline_report_zambia.pdf.

52. Kunthy S, Catalla RNF. Community-Led Total Sanitation (CLTS) in Cambodia. Final Evaluation. 2009.

53. Okullo JO, Moturi WN, Ogendi GM. Open defaecation and its effects on the bacteriological quality of drinking water sources in Isiolo County, Kenya. Environmental Health Insights. 2017;11.

54. Kevin B. Achieving "total sanitation" in rural African geographies: poverty, participation and pit latrines in Eastern Zambia. Geoforum. 2015;66:53-63.

55. Myers J, Gnilo M. Supporting the poorest and most vulnerable in CLTS programmes; 2017.

56. Busienei PJ, Ogendi GM, Mokua MA. Open defecation practices in Lodwar, Kenya: a mixed-methods research. Environmental Health Insights. 2019; 1178630219828370.
57. Evans BE, Colin C, Jones H, Robinson A. Sustainability and equity aspects of total sanitation programmes-a study of recent WaterAid-supported programmes in three countries: global synthesis report; 2009.

58. Robinson A. Sustainability and equity aspects of total sanitation programmes: a study of recent WaterAid-supported programmes in Nigeria. London: WaterAid; 2009.

59. SNV. Review of the Concern Worldwide CLTS Pilot in Houaphan. www.communityledtotalsanitation.org. 2009.

60. UNICEF. Community-Led Total Sanitation in East Asia and Pacific: progress, lessons and directions. Bangkok, Thailand.: East Asia and Pacific Regional Office, UNICEF; 2013.

61. Venkataramanan V. CLTS learning series: lessons from CLTS implementation in seven countries. NC: Chapel Hill; 2016.

62. Kwiringira J, Atekyereza P, Niwagaba C, Günther I. Descending the sanitation ladder in urban Uganda: evidence from Kampala Slums. BMC Public Health. 2014;14(1):1-10.

63. Andres H, Brian B. An untold story of policy failure: the Total Sanitation Campaign in India. Water Policy. 2013;15(6):1001-17.

64. Mosler H-J, Mosch S, Harter M. Is Community-Led Total Sanitation connected to the rebuilding of latrines? Quantitative evidence from Mozambique. PloS one. 2018:13(5):e0197483.

65. Phiri S. TA Mkanda CLTS Research Summary. Engineers without Borders Canada. 2010.

66. Hanchett S, Krieger L, Kahn MH, Kullmann C, Ahmed R. Long-term sustainability of improved sanitation in rural Bangladesh; 2011.

67. Sugden S. One step closer to sustainable sanitation: the experiences of an eco-sanitation project in Malawi. WaterAid, Malawi. 2003:1-14.

68. TWITTY M. On the road to sustainable sanitation: an overview of practices and lessons learned from a sanitation programme in Malawi. Waterlines. 2013;32(1):50-57.

69. Mukherjee N. Factors associated with achieving and sustaining open defecation free communities: learning from East Java. Water and Sanitation Program. 2011:1-8.

70. Ababa A. Federal Democratic Republic of Ethiopia Ministry of Health CLTSH Verification and Certification Protocol; 2012

71. Mukherjee N, Robiarto A, Saputra E, Wartono D. Achieving and sustaining open defecation free communities: learning from East Java. Report from WSP Washington, DC: World Bank. 2012.

72. Chambers R, Myers J. Norms, knowledge and usage; 2016.

73. Körner M, Svoboda D, Limberk O. Sierra Leone impact evaluation of Community Led Total Sanitation (CLTS) approach (2008-2015). ALNAP. 2011:

74. Angoua E, Larissa Eméline, Dongo K, Templeton MR, Zinsstag J, Bonfoh B. Barriers to access improved water and sanitation in poor peri-urban settlements of Abidjan, Côte d'Ivoire. PLoS ONE. 2018;13(8).

75. Prabhakaran P, Kar K, Mehta L, Chowdhury SR. Impact of Community-Led Total Sanitation on women's health in urban slums: a case study from Kalyani municipality. IDS, 2016.

76. Assembly UG. Transforming our world: the 2030 agenda for sustainable development, resolution adopted by the general assembly. A/70/L. 1. New York: UN General Assembly; 2015.

77. Hutton G, Haller L, Water S, Organization WH. Evaluation of the costs and benefits of water and sanitation improvements at the global level. World Health Organization, 2004

78. Acharya A, Paunio MK. Environmental health and child survival: epidemiology, economics, experiences. The World Bank, 2008.

79. Vyas S, Kov P, Smets S, Spears D. Disease externalities and net nutrition: evidence from changes in sanitation and child height in Cambodia, 20052010. Economics Human Biol. 2016:23:235-45.

80. National of Kenya 2020 Campaign framework. Republic of Kenya Ministry of Health, 2016.

81. Vogl TS. Height, skills, and labor market outcomes in Mexico. J Development Economics. 2014:2014(107):84-96.

82. Water U. Sustainable Development Goal 6 synthesis report on water and sanitation. Published by the United Nations New York, New York. 2018; 10017.

83. Dandabathula G, Bharadwaj P, C SR, Rao P, Burra M. Combating open defecation through community-led sanitation. Dr Sulaiman Al Habib Medical Journal. 2019 07/03;1. 
84. Chadwick E. Report on an inquiry into the sanitary condition of the labouring population of Great Britain. London: Her Majesty's Stationery Office; 1842. p. 279.

85. Feachem R, Bradley D, Garelick H, Mara D. Sanitation and disease: health aspects of excreta and wastewater management; 1983.

86. Larsen DA, Grisham T, Slawsky E, Narine L. An individual-level meta-analysis assessing the impact of community-level sanitation access on child stunting, anemia, and diarrhea: evidence from DHS and MICS surveys. PLOS Neglected Tropical Diseases. 2017;11(6):13.

87. Garn J, Boisson S, Willis R, Bakhtiari A, Alkhatib T, Amer K, et al. Sanitation and water supply coverage thresholds associated with active trachoma: modeling cross-sectional data from 13 countries. PLoS Neglected Tropical Diseases. 2018;12(1):e0006110.

88. Mara D, Lane J, Scott B, Trouba D. Sanitation and health. PLOS Medicine. 2010;7(11):1-7.

89. Prüss.pstün A, Bos R, Gore F, Bartram J, editors. Safer water, better health: costs, benefits and sustainability of interventions to protect and promote health 2008

90. Guerrant RL, DeBoer MD, Moore SR, Scharf RJ, Lima AAM. The impoverished gut-a triple burden of diarrhoea, stunting and chronic disease. Nat Rev Gastroenterol Hepatol. 2013;10(4):220-9.

91. Kwesiga B, Pande G, Ario AR, Tumwesigye NM, Matovu JKB, Zhu B-P. A prolonged, community-wide cholera outbreak associated with drinking water contaminated by sewage in Kasese District, Western Uganda. BMC Public Health. 2018;18(30):1-8.

92. GBD. Estimates of the global, regional, and national morbidity, mortality, and aetiologies of diarrhoea in 195 countries: a systematic analysis for the Global Burden of Disease Study 2016. Lancet Infect Dis. 2018;18:1211-28.

93. Anderson RM. The population dynamics and control of hookworm and roundworm infections. In: Anderson RM, editor. The population dynamics of infectious diseases: theory and applications. Boston: Springer US; 1982. p. 67-109.

94. Oyebamiji DA, Ebisike AN, Egede JO, Hassan AA. Knowledge, attitude and practice with respect to soil contamination by soil-transmitted helminths in Ibadan, Southwestern Nigeria. Parasite Epidemiol Control. 2018;3.

95. Delea MG, Solomon $H$, Solomon AW, Freeman MC. Interventions to maximize facial cleanliness and achieve environmental improvement for trachoma elimination: a review of the grey literature. PLOS Neglected Tropical Diseases. 2018;12(1):1-26.

96. Gryseels B, Polman K, Clerinx J, Kestens L. Human schistosomiasis. Lancet. 2006;368:1106-18

97. Colley DG, Bustinduy AL, Secor WE, King CH. Human schistosomiasis. Lancet. 2014 2014/06/28/;383(9936):2253-64

98. Grimes JET, Croll D, Harrison WE, Utzinger Jr, Matthew C. Freeman, Templeton MR. The relationship between water, sanitation and schistosomiasis: a systematic review and meta-analysis. PLOS Neglected Tropical Diseases. 2014;8(12):1-12.

99. Exum NG, Kibira SPS, Ssenyonga R, Nobili J, Shannon AK, Ssempebwa JC, et al. The prevalence of schistosomiasis in Uganda: a nationally representative population estimate to inform control programs and water and sanitation interventions. PLOS Neglected Tropical Diseases. 2019;13(8):1-21.

100. Yuniarni H, Haq FA, Rasyidah F, editors. The increased risk of schistosomiasis caused by high frequency of rainfall and open-defecation habit in Indonesia International Proceedings of Chemical, Biological and Environmental Engineering; 2016

101. Luby SP, Gupta SK, Sheikh MA, Johnston RB, Ram PK, Islam1 MS. Tubewell water quality and predictors of contamination in three flood-prone areas in Bangladesh. J Applied Microbiol 2008;105:1002-1008.

102. Rajgire AV. Open defecation: a prominent source of pollution in drinking water in villages. Int J Life Sci Biotechnol Pharma Research. 2013;2(1):238-46.

103. Jasper C, Le T-T, Bartram J. Water and sanitation in schools: a systematic review of the health and educational outcomes. Int J Environ Res Public Health. 2012;9:2772-87.

104. Organization WH. Helminth control in school-age children: a guide for managers of control programmes. 2nd ed. France: World Health Organization; 2011

105. Trinies V, Garn JV, Chang HH, Freeman MC. The Impact of a school-based water, sanitation, and hygiene program on absenteeism, diarrhea, and respiratory infection: a matched-control trial in Mali. Am J Trop Med Hyg. 2016;94(6):1418-25.
106. Morrissey TW, Hutchison L, Winsler A. Family income, school attendance, and academic achievement in elementary school. Developmental Psychol. 2014;50(3):741-53.

107. Mahon T, Fernandes M. Menstrual hygiene in South Asia: a neglected issue for WASH (water, sanitation and hygiene) programmes. Gender Development. 2010;18(1):99-113.

108. Pearson J, Mcphedran K. A literature review of the non-health impacts of sanitation. Waterlines. 2008;27(1):48-61.

109. Hutton G, Chase C. The knowledge base for achieving the sustainable development goal targets on water supply, sanitation and hygiene. Int J Environ Res Public Health. 2016;13(536):1-35.

110. Abioye-Kuteyi EA. Menstrual knowledge and practices amongst secondary school girls in lle Ife, Nigeria. The Journal of the Royal Society for the Promotion of Health. 2000;120(1):23-6.

111. Lamdin DJ. Evidence of student attendance as an independent variable in education production functions. The Journal of Educational Research. 1996; 89(3):155-62.

112. Gakidou E, Cowling K, Lozano R, Murray CJL. Increased educational attainment and its effect on child mortality in 175 countries between 1970 and 2009: a systematic analysis. Lancet. 2010;376:959-74.

113. Moh E. Health Sector Development Programme IV. Addis Ababa: MOH, 2011

114. Office NWC. Federal democratic republic of Ethiopia - CMP COWASH Ethiopia. National Wash Coordination Office, 2018.

115. Commission NP. The second growth and transformation plan (GTP II)(2015/ 16-2019/20)(draft). Addis Ababa: the Federal Democratic Republic of Ethiopia, 2015

116. Supply W, Sector S. The Federal Democratic Republic of Ethiopia Ministry of Water Irrigation and Energy. cmpethiopia.org, 2019.

117. Page I. Federal Democratic Republic of Ethiopia National Hygiene and Environmental Health Strategy Implementing Sectors Declaration; 2016.

118. Yuniarni H, Haq F, Rasyidah F. The increased risk of schistosomiasis caused by high frequency of rainfall and open-defecation habit in Indonesia. IPCBEE. 2016;93(2):9-16.

119. Clarke N, Clements A, Amaral S. (S)WASH-D for Worms: a pilot study investigating the differential impact of school versus community-based integrated control programs for soil-transmitted helminths. PLoS neglected. 2018;12(5):e0006389.

120. Organization WH. Waterborne outbreaks of hepatitis E: recognition, investigation and control: World Health Organization; 2014

\section{Publisher's Note}

Springer Nature remains neutral with regard to jurisdictional claims in published maps and institutional affiliations.

Ready to submit your research? Choose BMC and benefit from:

- fast, convenient online submission

- thorough peer review by experienced researchers in your field

- rapid publication on acceptance

- support for research data, including large and complex data types

- gold Open Access which fosters wider collaboration and increased citations

- maximum visibility for your research: over $100 \mathrm{M}$ website views per year

At $\mathrm{BMC}$, research is always in progress.

Learn more biomedcentral.com/submissions 